\title{
Comparative Analysis of Proximal and Distal Determinants for the Acceptance of Coercive Charging Policies in the UK and Japan
}

\section{$\operatorname{AUTHOR}(\mathrm{S})$ :}

Schmöcker, Jan-Dirk; Pettersson, Pierre; Fujii, Satoshi

\section{CITATION:}

Schmöcker, Jan-Dirk ... [et al]. Comparative Analysis of Proximal and Distal Determinants for the Acceptance of Coercive Charging Policies in the UK and Japan. International Journal of Sustainable Transportation 2011, 6(3): 156-173

\section{ISSUE DATE:}

2011-10

URL:

http://hdl.handle.net/2433/172932

\section{RIGHT:}

(C) Taylor \& Francis Group, LLC; この論文は出版社版でありません。引 用の際には出版社版をご確認ご利用ください。; This is not the published version. Please cite only the published version. 


\title{
Comparative Analysis of "Deeper" Determinants for the Acceptance of Coercive Charging Policies in the U.K. and
} Japan

\author{
Jan-Dirk Schmöcker \\ Department of Urban Management, Kyoto University, C1-2-431, Nishikyo-ku, \\ Kyoto 615-8540, Japan, Tel: +81-75-383-3239, Fax: +81-75-383-3236, fujii@trans.kuciv.kyoto-u.ac.jp
}

Pierre Pettersson

Department of Civil and Environmental Engineering, Tokyo Institute of Technology, 2-12-1, Ookayama, Meguro-ku, Tokyo, 152-8552, Japan, Tel/Fax: +81-3-5734-2577, pierre_traba@hotmail.com

\author{
Satoshi Fujii \\ Department of Urban Management, Kyoto University, C1-2-431, Nishikyo-ku,
} Kyoto 615-8540, Japan, Tel: +81-75-383-3238, Fax: +81-75-383-3236, fujii@trans.kuciv.kyoto-u.ac.jp

\begin{abstract}
Coercive policies, such as road pricing or environmental taxation, are policies of an authority that charges or restricts its subjects with the aim to protect or restore common goods. Road pricing examples have shown that it is important to understand the acceptability of such policies to the general public in order to guarantee the long term success. This paper investigates the underlying factors that determine acceptability of coercive charging policies. There are a number of well-established psychological factors that determine acceptability directly or indirectly such as perceived effectiveness, fairness or problem awareness. This paper proposes that trust in government is another significant factor. We investigate the relationship between trust in government and other factors through structural equation modelling. Our results show that trust in government plays a central role for acceptance. We therefore further discuss what factors can influence a general trust in governments and show that among a British sample one determinant is a person's belief in "absolute values" defined here as the belief that objective truths, true justice and an authentic beauty in this world exist. Our analysis is based on a survey among British and Japanese students asking about acceptability for a hypothetical scenario of environmental taxation to finance the introduction of $\mathrm{CO}_{2}$ emission reducing technologies.
\end{abstract}

Keywords: $\quad$ Acceptability, Environmental taxation, Road Pricing, Government Trust, Absolute values 


\section{Introduction}

Coercive policies are defined as policies of an authority that charge or restrict its subjects with the aim to protect or restore common goods. Prime examples for these are environmental taxation or, in the case of transport planning, more specifically, road pricing. Such coercive policies are seldom cheered by those who have to pay but in some cases accepted. Clearly the details of a proposed scheme will have an influence on its acceptance. For example in Edinburgh the feared effects of a proposed tax to enter the city centre by car on the local economy raised many concerns, leading eventually to its rejection (Gaunt et al., 2007). Though some might simply reject such coercive policies when realising that they will have to pay or, even worse, when realising who proposed it without seeing the details. Recent findings and wide-spread publications or documentary movies such as "An Inconvenient Truth" (www.climatecrisis.net) have further triggered a renewed discussion on climate change and with it a discussion whether coercive policies are needed to mitigate the likely effects. Räthzel and Uzzell (2009) point out the concern of students in the U.K. and Sweden regarding environmental degradation. Their findings reveal that a majority of respondents expects governments to find solutions for urgent environmental problems although the main reasons for environmental degradation are seen to be individual behaviour and "society". The same would probably hold true if students were asked specifically about environmental problems caused by traffic.

Nowadays most governments agree that at least some coercive measures are needed to derive sustainable transport policies. and are concerned about the acceptance of such in the population. Acceptability to the public is seen as important not only for "winning the next election" but also because enforcement of violators is expensive and related to this is the fear of economic loss if the scheme is not accepted. In London, for example, it could be observed that, at least initially, some people replaced shopping trips previously done in Central London by diverting to stores not affected by the charge (Quddus et al., 2007). Schmöcker et al. (2006) suggest that this is partly due to drivers from Greater London avoiding the congestion charging zone. They speculate that this is partly due to unfamiliarity with the scheme, despite widespread publicizing in Greater London, which will be linked to acceptance. A person more likely to accept or even support a scheme will also more likely be willing to inform himself how to pay the charge. There are established psychological constructs that can explain the acceptability of road pricing or car usage restrictions. Several studies have shown that factors relating to the respondents personal circumstances, his attitude towards the scheme introducing government as well as factors related to the scheme itself can explain possibly acceptance fairly well. One might refer to the constructs "infringement on freedom", "fairness", "problem awareness", and "perceived effectiveness" hence as psychological determinants as they directly or indirectly explain acceptability. 
In this study, partly following Fujii (2005), we propose "trust in government" as deeper determinant of acceptance. We further explore whether a newly established determined "belief in absolute" is a determinant of trust in government in turn. Finally, our aim is to understand whether there are significant cultural differences, especially regarding the role of trust in government. The remainder of this paper is organized as follows. The following section reviews the psychological factors that have been found important to gain acceptance for road pricing. Section 3 then describes in more detail our arguments for the presumption that trust in government and belief in absolutes might be "deeper" factor explaining acceptance via the established psychological factors as well as our reasoning why we presume that these factors might be culturally dependent. Our presumptions are tested with a hypothetical scenario posed to students in Japan in Britain. This survey is described in Section 4. Section 5 analyses the survey results through correlation analysis and structural equation modelling. Section 6 then summarizes the findings and discusses the implications.

\section{Presumptions regarding determinants of road pricing}

\subsection{Summary of established determinants}

Despite global environmental problems, the details of any proposed coercive policy vary obviously in each case as the problems and needs of each city or country differ. Psychological literature attempts to understand general factors that make coercive policies acceptable. The question might be posed as: "What are the underlying factors that convince people that the general or public benefits outweigh a person's individual costs?" On the one hand the economists approach to this is to attempt to measure the total combined utility of a person, made up of both individual as well as public costs and benefits. On the other hand psychological literature proposes that attitudes and perceptions might describe acceptability better. In particular following six factors have been shown to influence acceptability significantly:

Firstly, the perceived fairness of a scheme. For example Jakobsson et al. (2000) show that if road pricing is perceived to be fair, acceptability significantly increases. The term fairness can be further split up into fairness of the scheme itself (or general fairness), distributional fairness and procedural fairness, all being shown to have significant effects on governmental policy (cf. Lind and Tyler, 1988). Distributional fairness relates to the perceived equality of the scheme, e.g. whether some population groups might be overly disadvantaged compared to others. Procedural fairness relates to the way the scheme was introduced. For example a scheme being introduced by a politician without sufficient consultation of experts might not be accepted. US experiences suggest that procedural fairness is 
as important as distributive, since proposals in which the population was included fairly early did raise far less objections later on (Taylor et al., 2010). Similarly, Ecola and Light (2010) recommend that equity concerns should be addressed early during the planning stages, emphasising the importance of both distributive and procedural fairness.

Secondly, perceived effectiveness. Bamberg and Rölle (2005) discuss that convincing the public about the effectiveness of a scheme is key to gain support. Taylor et al. (2010) review recent proposals for road pricing schemes in the US. They suggest that a clear definition of the goals, be it revenue collection or congestion reduction, as well as making a clear case whether this is going to be achieved, are key to gain acceptance. Steg (2003) and Jones (2003) discuss that perceived effectiveness is further linked to policy consistency. A scheme is less likely to be supported if the government's policy in other areas is seen to be contrary to the proposed schemes objectives.

Thirdly, infringement on freedom. This term describes what effect the proposed charge has on the person. "Freedom" is a term that can have several connotations. In the context of road pricing it is most often associated with the financial burden reducing ones financial freedom. In other transport policy contexts it might be rather associated with the freedom of movement, if for example roads might be closed for some travellers or stricter speed or drink \& drive legislations are introduced limiting one's choices of how fast to drive or how much to drink. Clearly, higher infringement on freedom is expected to reduce acceptance; that is the higher the charge, the higher the infringement (cf. Barron and Jurney, 1993; Jakobsson et al., 2000). The perception of infringement might be reduced though if the person can be compensated by other benefits. Schaller (2010) reports that the proposed pricing scheme in New York City might have been implemented if more drivers could have been convinced that the scheme would have benefited themselves. Currently for most city centre road pricing schemes, whether proposed or already in operation, the revenue is mainly used to improve public transport. Ecola and Light (2010) suggest that to reduce opposition the revenue might be better used for tax exemptions to those having to pay. Though possibly reducing the effectiveness of the scheme this could have a more positive effect on perceived fairness as well as infringement on freedom.

Fourthly, social problem awareness. Schade and Schlag (2003) for example provide evidence that only those who are convinced that the car is a major pollutant will be convinced that a road user charge might be needed. Gärling et al. (2008) report that social problem awareness is an important factor when discussing road user charging acceptance in Sweden. Schaller (2010) notes that in the public discussion about the introduction of road pricing in Manhattan, New York, it was important for people that the scheme has positive effects both on the societal as well 
as individual level.

Fifthly, self problem awareness. In contrast to social problem awareness this factor relates to the awareness that "my own behaviour is part of the problem" as discussed for example by Choocharukuland and Fujii (2007). They point out that it is important to distinguish social and self problem awareness as one might understand that there is a problem but consider one's own contribution too minor to be of any relevance. Self problem awareness hence relates to the awareness of responsibility for the problem whereas the former two forms of problem awareness relate to the existence of a (social and personal) problem.

Sixthly, and related to perceived effectiveness as well as social problem awareness, personal problem awareness. This factor describes whether a person perceives the problem to be significantly related not just to the public in general but to him personally (cf. Gärling et al., 2003; Schade and Schlag, 2000). For example, those experiencing congestion daily, might be more willing to accept a road charge aiming to reduce pollution as well as congestion. Piriyawat et al. (2009) find that in Bangkok social problem awareness is not significant but that personal problem awareness is. Jakobsson et al. (2000) further report that car use reduction has a negative (indirect) effect on acceptance of road pricing, in other words those who will reduce their car use because they do not want to, or cannot, afford to pay the charge, support the scheme less. This implies that besides social, also personal, egoistic motives are related to acceptance in Sweden.

\subsection{Structure of determinants}

These six factors are likely to vary in their directness of influencing acceptance. In particular one might distinguish determinants that directly depend on the proposed policy, such as perceived effectiveness, fairness and infringement. Our factors four to six, the different forms of problem awareness, do not depend on the scheme details and might influence acceptance but also the scheme specific factors in turn. In the following we refer to such factors as "deeper" factors. This ordering of determinants is similar to the discussion on values, beliefs, attitudes and behaviour in Rokeach (1973). He describes that behaviour is influenced by attitudes and values. Attitudes are in general "focused on a given object or situation", in other words, towards a specific policy or problem a person will have a specific attitude. Attitudes will be determined in turn by a person`s values which might be similarly described as "deeper factors". A value refers to single beliefs regarding a "desirable mode or end-state" that is independent of specific scenarios. Examples for values are the importance of peace, comfort or freedom to a person. Rokeach writes that values occupy a more central role in one's personality makeup and hence possibly also revealed behaviour. Therefore this study will also focus on deeper factors, in other words what are the factors that determine 
the scheme specific attitudes and again what values determine these factors in turn.

Rokeach (1973) notes that the importance of values and attitudes is often culture dependent. Similarly, we investigate whether the structure of determinants of acceptance is different across different countries. For example Fujii et al. (2004) confirm that determinants such as fairness and infringement on freedom transcend culture but that the relative importance of some factors, for example income effects, differs between Asian and European countries. Therefore, we analyze determinants of acceptance in two different countries, in this study Japan and the U.K.. Our aim is to understand possible differences in the way these determinants affect acceptance. Räthzel and Uzzell (2009) criticize that previous studies on psychological theories to explain optimism regarding the state of the environment are "ahistoric and decontextualised". Though this study concerns the acceptance of policy and not the perception of the environment state, this study might hence also be a step to better understand the impact of history and culture on environmental policies.

\section{Trust in government and absolutes as deeper determining factors}

\subsection{Trust in government as determinant of acceptance}

Although the effects of above determinants on acceptance, and the relation between these has been well studied, "deeper" determinants that determine these in turn, have not well been investigated. A rare example includes Fujii (2005), who discusses that acceptance will depend partly on whether the government in general is trusted and whether it is trusted that for example revenues are used in the way proposed in the scheme. Using data from a Japanese sample, it was found that trust in government has direct effects on acceptance, fairness, infringement on freedom as well as perceived effectiveness. Following Hardin (1999), the rationale is that those who trust in the government also more likely have trust that its policy measures are effective and fair, so that their acceptance tends to be higher than that of others. Further, if one trusts the government, one may expect the government to introduce less harmful policies (i.e. less infringement on freedom). Note that it was not found that problem awareness is influenced by the perception of government. This is understandable as it implies that problem awareness is not related to the government performance, but rather it is a cognitive understanding of the objective problems.

An objective of this study is to investigate whether trust in government is a similarly important deeper determinant for the acceptance of coercive policies in Western countries as in Japan. To the best of our knowledge this has not yet well been empirically tested outside of Japan. It is though reasonable to assume that it is a deeper determinant 
of acceptance, as implied by Taylor et al. (2010). They conclude that the often complex governmental structures in the U.S., together with a lack of trust in and between these, are a major obstacle for road pricing implementations.

\subsection{Explorative Research: Belief in Absolute as determinant of government trust}

Following on from this hypothesis our study makes one additional step. Offe (1999) discusses that trust is generally influenced by one`s cultural background including his/her religious beliefs. Our assumption is that this might be true across cultures despite the fact that religious beliefs vary across countries or cultures. Our aim is to define a culture independent term for beliefs connected to trust in government. In other words, it might not be appropriate to use the term "belief in God" in a non-Christian context or to use an Buddhist image in a Christian country. Therefore, with this recognition, we define "beliefs in absolute" as a further deeper determinant of acceptance which we hypothesise to influence trust in government. We define this determinant as a belief that there is objective truth, true justice and an authentic beauty in this world. That is, a person believes that at least some of his/her values are not merely depending on the person's background and perceptions, but that values transcend culture. The opposite to this would be a person who beliefs "everything is relative", in other words there is no truth that can be judged objectively. We presume that religious beliefs and our determinant belief in absolute has a positive influence on government trust, since, similar to "God" or "absolutes", governments are generally seen as superior and trustworthy. ${ }^{1}$

Though we expect to see in principal the same relationships between "belief in absolute" and other factors across cultures, the effect might be much clearer in some. In particular there might be a difference between the two countries compared in this study. Whereas Britain has a long history of a central monarchy being strongly connected to the governing religion, Japanese history is characterized by a very hierarchical society and a country split into many governing prefectures. More importantly, in the past British, or in general Western, culture was dominated by Christian monotheistic beliefs. Nowadays the influence of such monotheistic, absolute views is, however, much

\footnotetext{
${ }^{1}$ Note that our determinant is different to the ones included in the established value belief norm theory that determine pro-environmental behaviour. One might expect some correlation between for example universalism or benevolence and belief in absolute values as all three should discourage egoistic beliefs or the importance of self-enhancement. However, there are conceptually also clear differences. Universalism, as used in the literature to describe basic human values, rather refers to a "broad-minded" person aiming for social justice and world peace (Schwartz, 1992). Contrary to this, belief in absolute might be rather described as a belief that there would be values that should be globally accepted. There might be some similarities to benevolence which is characterized with terms such as "helpful, forgiving or responsible" in Schwartz (1992, 1994) and subsequent works (e.g. Schultz and Zelezny 1999; Hansla et al., 2009), but our term "belief in absolute" is rather defined value free. Though it might be difficult to imagine that one would hold absolute values opposing those included in benevolence, beliefs such as that there is an authentic beauty or true justice do not define any value.
} 
reduced in a secularized society, leading to a sometimes sharp division. On one side there is a group believing in absolute values, on the other side there is a group advocating that religions and other movements cannot make any absolute claims. In Japan the situation is different. For a long time the country has been dominated by values originating in Buddhism and nature religion. These might also be described as "absolute values", though claims of "universal absoluteness" are less pronounced as in Christianity. Similar to Western culture, also Japanese society is nowadays changing fast but open rebellion against Buddhist religion can rarely be observed. In the vast majority the influence of religion on Japanese individuals' beliefs has been reduced, but many religious customs are upheld. Further, behaviour in Japanese society might be often dominated by social norms (Triandis, 1995). Hence the individual's support or rejection of absolute ideas probably does not influence his/her behaviour as clearly and directly as in Western culture, since such social norms might be covertly regarded as a proximal determinant that reflect absolute ideas. Based on these observations we expect that in Britain the effects of "belief in absolute" on acceptance of coercive policies can be seen much clearer.

\section{Hypothetical scenario and survey design}

To achieve our objectives we designed a survey asking students in London and Tokyo about their acceptance of a hypothetical scenario of environmental taxation as well as their attitudes towards government and their belief in absolute values. Though using a road pricing scenario might also be feasible we decided to use this example as traffic problems will always have strong associations with local experiences which are more difficult to control for. Further, students in both samples are likely to have different associations with road pricing. Londoners will be familiar with road pricing in the form of Congestion Charge, whereas students in Tokyo most likely have experiences of road pricing in the form of charges required for highway usage. Global warming, however, is, by definition, a global issue which most students can be assumed to be familiar with. Therefore, we use a scenario of more general charging policy rather than road pricing in order to understand determinants of road pricing acceptance while investigating similarities and differences between two samples. Following scenario was posed to the students in London:

"The UK government has decided to introduce an environmental tax of $£ 50$ per month to be paid by all UK residents including all university students. The decision was made after a long debate with several economists and scientists through which the government got convinced that this additional tax is needed to influence greenhouse emissions. The tax will be used for environmental research and to subsidise the introduction of new technology that emits less CO2. The government accounted that they justified the amount by scientific research referring to the carbon footprints." 
Students in Tokyo were asked the same survey in Japanese with " $f 50$ " replaced by "Yen 10,000" and UK replaced by "Japan" or "Japanese". Clearly the scenario given is fairly vague. Consciously we omit further information to trigger stronger perceptions on whether such a scenario can possibly be fair, effective and acceptable. $f 50$ or Yen 10,000 is believed to be substantial for students, imposing some infringement on (financial) freedom, but still affordable. The statement "after a long debate with several economists and scientists" provided sufficient divergence in the perceived effectiveness as well as procedural fairness. Similarly, the fact that all residents are asked to pay was perceived as fair by some, whereas others probably thought such a tax should be based on income or actual $\mathrm{CO}_{2}$ emissions. All questions were asked on a 7 point Likert scale.

The surveys were conducted in paper form asking students at the end of classes to take $15 \mathrm{~min}$ to fill in the survey. The Japanese surveys were conducted at Tokyo Institute of Technology in October 2008 and at Imperial College London in November 2008. Students from all grades were included in the survey. With regards to the objectives of this study we ignored all foreign students leaving us with a valid sample for our subsequent SEM analysis of 72 students from Imperial College London and 139 students from Tokyo Institute of Technology answering all questions. The average of our samples is fairly similar with 22.6 years (std. dev. 2.2) in Japan and 21.2 years (std. dev. 1.8) in the U.K. Since mostly classes within the departments of Civil and Environmental Engineering at two predominantly technical universities were targeted not surprisingly our sample contains more male students, in particular in the Japanese sample (British: 56.9\% male, Japanese: $92.8 \%$ male). Initial regression analysis suggests that age and gender do not have a significant influence on acceptance, though this might of course be due to our sample biases.

The questions regarding acceptance and attitudes towards government as well as the proposed scheme were asked fairly straightforward (Table 1). Acceptance was measured with the two questions (Cronbach alpha 0.86 in the British and 0.91 in the Japanese sample). To increase reliability similarly social problem awareness was constructed by taking the mean of two questions (Cronbach alpha 0.90 in the British and 0.73 in the Japanese sample). Perceived fairness was asked with three questions. As the importance of these different fairness aspects might be different between cultures we decided to keep these three factors separate (scenario fairness, distributive fairness, procedural fairness). Also the other factors were measured with single questions as shown in Table 1. 
Table 1 Questions used to measure Acceptance and its determinants

\begin{tabular}{|c|c|}
\hline \multirow[t]{2}{*}{ Acceptance } & Are you willing to accept this governmental decision for an environmental tax? \\
\hline & Do you support this governmental decision for an environmental tax? \\
\hline Scenario Fairness & Do you think this environmental tax is fair? \\
\hline Distributive Fairness & Do you think this environmental tax is impartial? \\
\hline Procedural Fairness & Do you think this process of governmental decision making is fair? \\
\hline $\begin{array}{l}\text { Infringement on } \\
\text { Freedom }\end{array}$ & Do you think this environmental tax 'infringes on your freedom'? \\
\hline Effectiveness & $\begin{array}{l}\text { Do you think a tax like this can help to eventually reduce the effect of global } \\
\text { warming? }\end{array}$ \\
\hline \multirow{2}{*}{$\begin{array}{l}\text { Social Problem } \\
\text { Awareness }\end{array}$} & How serious do you feel the global environmental problem is? \\
\hline & Do you think global warming will seriously damage our society? \\
\hline $\begin{array}{l}\text { Self Problem } \\
\text { Awareness }\end{array}$ & $\begin{array}{l}\text { Do you think the } \mathrm{CO}_{2} \text { that you produce in your daily life will contribute to global } \\
\text { warming and this will negatively influence our society }\end{array}$ \\
\hline $\begin{array}{l}\text { Personal Problem } \\
\text { Awareness }\end{array}$ & Do you think global warming will seriously damage yourself? \\
\hline Trust in Government & Do you trust the government that made a decision to introduce this tax? \\
\hline
\end{tabular}

Finally, to measure our determinant belief in absolute following three statements were asked to students, asking, again on a 7 point Likert scale, how much they agree with these:

- I think there is an objective truth in the world.

- I think there is an "authentic beauty" (in society and nature) which is true for all nations and all times.

- I think there is a "true justice" which is true for all nations and all times.

Analysis of consistency between the questions using Cronbach's alpha showed a somewhat acceptable value of 0.63 for the Japanese sample and 0.51 among the British sample (0.59 for $\mathrm{N}=75$, all British students answering these 3 questions but omitting answers to some of the other questions). Removing any single question does not lead to a significant improvement in the consistency of the latent construct "Belief in Absolute". Though the questionnaire was tested and several questions reworded before the survey was conducted, one reason for the low alpha might be possible misunderstandings about the terms "objective truth", "authentic beauty" and "true justice". In further research one might test if rephrasing leads to better consistency. We emphasise that due to this limitation one might be slightly cautious regarding our results regarding belief in absolutes. Additional correlation analysis (for brevity omitted) shows though that taking the single questions on "objective truth" or "true justice" instead of our latent construct show similar correlations for both the Japanese and British sample as those discussed in the following. 


\section{Analysis and Results}

\subsection{Descriptive Analysis}

Our analysis shows that there is a similar mean acceptance of the scenario among the Japanese and the British sample (Table 2). The slightly higher acceptance in the Japanese sample is not statistically significant. The standard deviation is fairly large, allowing us to pick up differences in acceptance through our independent variables. Scenario fairness is significantly higher among the Japanese sample, whereas distributive fairness is significantly higher in the British sample. This suggests that the Japanese sample considers the scenario itself as fairer, but has more concerns about the equity of this environmental taxation. Whereas the differences in infringement on freedom and trust in government are both insignificant, social problem awareness, self problem awareness, personal problem awareness are significantly higher in the Japanese sample. This suggests that the Japanese students who took part in our survey rate the consequences of global warming as more significant. These are consequences for society, for themselves as well as awareness that the respondent's own lifestyle contributes to global warming. Perceived effectiveness is also higher in the Japanese sample suggesting that the British students have less trust that such a tax can alleviate the problem. Finally, the mean value of belief in absolute is slightly higher in the British sample, though not significantly.

Table 2: Mean and Std. dev. of acceptance and proposed determinants

\begin{tabular}{|l|r|r|r|}
\hline & \multicolumn{1}{l|}{ British } & \multicolumn{1}{l|}{ Japanese } & \multicolumn{1}{c|}{ t-test } \\
\hline Acceptance & $3.06(1.75)$ & $3.22(1.62)$ & 0.65 \\
\hline Scenario Fairness & $2.68(1.73)$ & $3.49(1.63)$ & $\mathbf{3 . 3 5}$ \\
\hline Procedural Fairness & $3.04(1.64)$ & $3.45(1.53)$ & 1.77 \\
\hline Distributive Fairness & $3.56(1.63)$ & $2.88(1.52)$ & $\mathbf{- 3 . 0 5}$ \\
\hline Infringement on Freedom & $3.90(1.81)$ & $3.58(1.78)$ & -1.26 \\
\hline Effectiveness & $3.32(1.79)$ & $4.27(1.52)$ & $\mathbf{4 . 0 4}$ \\
\hline Social Problem Awareness & $5.32(1.54)$ & $5.74(1.13)$ & $\mathbf{2 . 2 8}$ \\
\hline Self Problem Awareness & $4.38(1.74)$ & $5.14(1.38)$ & $\mathbf{3 . 7 4}$ \\
\hline Personal Problem Awareness & $3.57(1.86)$ & $4.56(1.58)$ & $\mathbf{4 . 0 7}$ \\
\hline Trust in Government & $3.22(1.43)$ & $3.34(1.41)$ & 0.56 \\
\hline Belief in Absolute & $4.17(0.77)$ & $3.97(1.01)$ & -1.50 \\
\hline
\end{tabular}

\subsection{Correlation analysis of acceptance}

We firstly test whether the determinants in Table 2 are correlated with acceptance. This will help us to understand in our subsequent SEM analysis which effects are mitigated. To clarify whether there are cultural differences the analysis is conducted separately for both countries. 
Table 3 shows that the three fairness determinants, effectiveness, infringement on freedom, trust in government and social problem awareness are all significantly related to acceptance for both Japanese and British samples. These results indicate that the determinants of acceptance are similar between Japanese and British samples. Yet, there are some differences between the Japanese and British sample: Firstly, the highest correlation between acceptance and a determinant is found to be "fairness" for the British sample, but "trust in government" for the Japanese sample. Secondly, the average correlation is larger in the British sample. This is confirmed by additional regression analysis with the determinants as explanatory variables which shows that the model fit of acceptance is larger for the British sample $\left(R^{2}=.73\right)$ than for the Japanese sample $\left(R^{2}=.53\right)$. Thirdly, belief in absolute is highly significant in the British sample but not at all in the Japanese.

Table 3: Correlation between acceptance and its hypothesized determinants (bold: significant on $5 \%$ level; bold *: significant on $1 \%$ level)

\begin{tabular}{|l|r|r|}
\hline & Japanese & \multicolumn{1}{|c|}{ British } \\
\hline Scenario Fairness & $\mathbf{0 . 5 6}^{*}$ & $\mathbf{0 . 7 3}^{*}$ \\
\hline Procedural Fairness & $\mathbf{0 . 4 3}^{*}$ & $\mathbf{0 . 6 5}^{*}$ \\
\hline Distributive Fairness & $\mathbf{0 . 3 8}^{*}$ & $\mathbf{0 . 2 8}$ \\
\hline Infringement on Freedom & $\mathbf{- 0 . 3 2}^{*}$ & $\mathbf{- 0 . 4 5}^{*}$ \\
\hline Effectiveness & $\mathbf{0 . 3 6}^{*}$ & $\mathbf{0 . 6 8}^{*}$ \\
\hline Social Problem Awareness & $\mathbf{0 . 2 2}$ & $\mathbf{0 . 3 8}$ \\
\hline Self Problem Awareness & 0.15 & 0.04 \\
\hline Personal Problem Awareness & 0.12 & 0.16 \\
\hline Trust in Government & $\mathbf{0 . 6 1}$ & $\mathbf{0 . 5 1}$ \\
\hline Belief in Absolute & 0.06 & $\mathbf{0 . 3 8}$ \\
\hline
\end{tabular}

\subsection{SEM analysis}

Figures 1 and 2 show the results of our SEM analysis for the Japanese and British sample respectively. From right to left the determinants of acceptance are ordered in accordance to their hypothesised "deepness". On the left hand side of the figures is belief in absolute which we hypothesised to influence trust in government. Trust as well as the three forms of problem awareness are then supposed to influence the scheme specific determinants of perceived fairness (in its three forms), perceived effectiveness and infringement of freedom. On the most right is acceptance itself. The models only include paths that are significant at the $5 \%$ level from deeper to higher level determinants as well as significant correlations between the three different forms of problem awareness and between the scheme specific attributes. The model fit of both models is acceptable though the model fit for the Japanese sample is better, possibly because of the larger sample size (Japanese sample: $\chi 2=36.2, \mathrm{DF}=55, \mathrm{GFI}=0.95$, Adjusted GFI $=0.93, \mathrm{CFI}=$ 1.00; British sample: $\chi 2=54.9, \mathrm{DF}=55, \mathrm{GFI}=0.88$, Adjusted $\mathrm{GFI}=0.82, \mathrm{CFI}=0.96)$. 
Our results illustrate the importance of trust in government as a deeper determinant in both samples. A higher trust in government is positively associated with all fairness determinants as well as perceived effectiveness. In the Japanese sample it is especially perceived scenario fairness as well as distributive fairness that are influenced by trust. Trust in government is also of comparable importance for all fairness determinants in the British sample. This can be easily explained; those who trust the government are also more likely to belief that the government policy is fair in terms of the policy itself, how it is established as well as its specific distributive effects. Similarly the effects of trust in government on perceived effectiveness and infringement on freedom are significant and have the expected signs. The willingness to endure some personal costs is in both cases similarly related to government trust. Our results regarding the effect of trust in government on perceived effectiveness possibly indicates that in the British sample perception of policy success and general government success are closely related. In the Japanese sample perceived effectiveness is further significantly influenced by self problem awareness, meaning that those who understand that their own behaviour is part of the problem are also more likely to understand that effective policies need to be introduced to solve the problem. Further a surprising negative path from personal problem awareness to scenario fairness is found in the Japanese sample, possibly indicating ignorance, but this effect should be investigated in further research.

Acceptance is determined by fairness aspects, perceived effectiveness and infringement in the British sample in line with previous literature using European data samples (Jakobsson et al., 2000; Bamberg and Rölle, 2005), whereas in our Japanese sample effectiveness and infringement are not significant. It is rather the non-mediated effect of trust itself that significantly determines acceptance in Japan. Combining the results of Table 3 and Figure 1 one can see that the effect of trust in government in the British sample is mitigated through the scheme specific determinants. We believe this is an important result as it indicates that in Japan the non-scheme specific performance of a government is important to obtain acceptance, whereas in the British sample it is foremost the scheme specific details that determine acceptance. In the Japanese sample it is further social problem awareness which influences acceptance confirming similar effects found by Gärling et al. (2008) in Sweden. Further analysis shows that this path in the British sample is also significant on the $10 \%$ level.

Finally, our explorative research regarding the role of belief in absolute on trust in government reveals that the effect is positively significant in the British sample but not significant in the Japanese sample. Table 3 also shows the significant relationship between belief in absolute and acceptance in the British but not the Japanese sample. Additional detailed mediation analysis based on linear regression analysis confirms that belief in absolute could be a deeper factor of acceptance which is mediated by trust in government as well as scenario fairness, procedural 
fairness, infringement and effectiveness (all four significant paths in Figure 2).

Belief in absolute

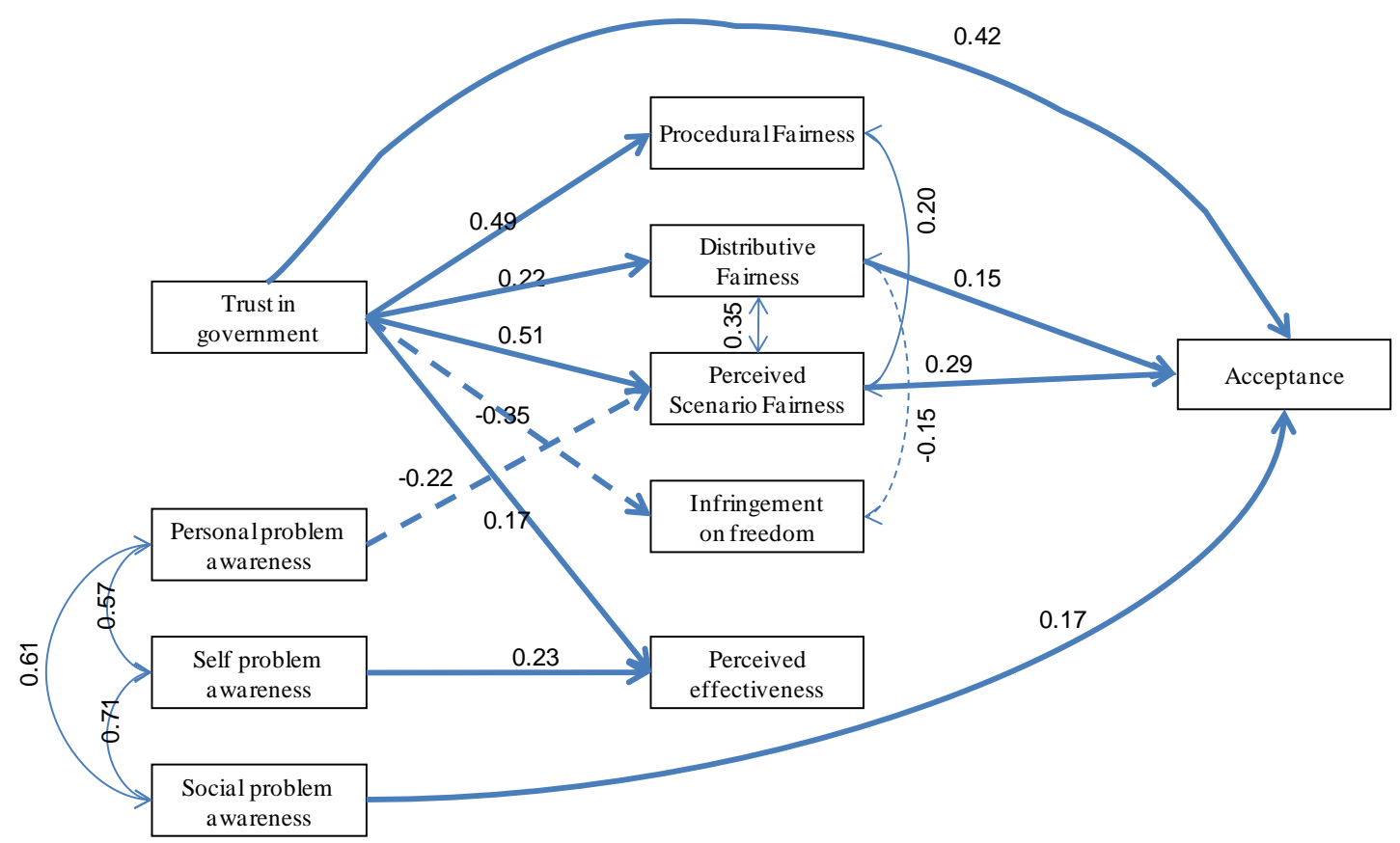

Figure 1 SEM Analysis results of our Japanese sample (thick arrows indicate paths significant at the $5 \%$ level; thin two-way arrows indicate correlations, dotted arrows indicate negative paths/correlations)

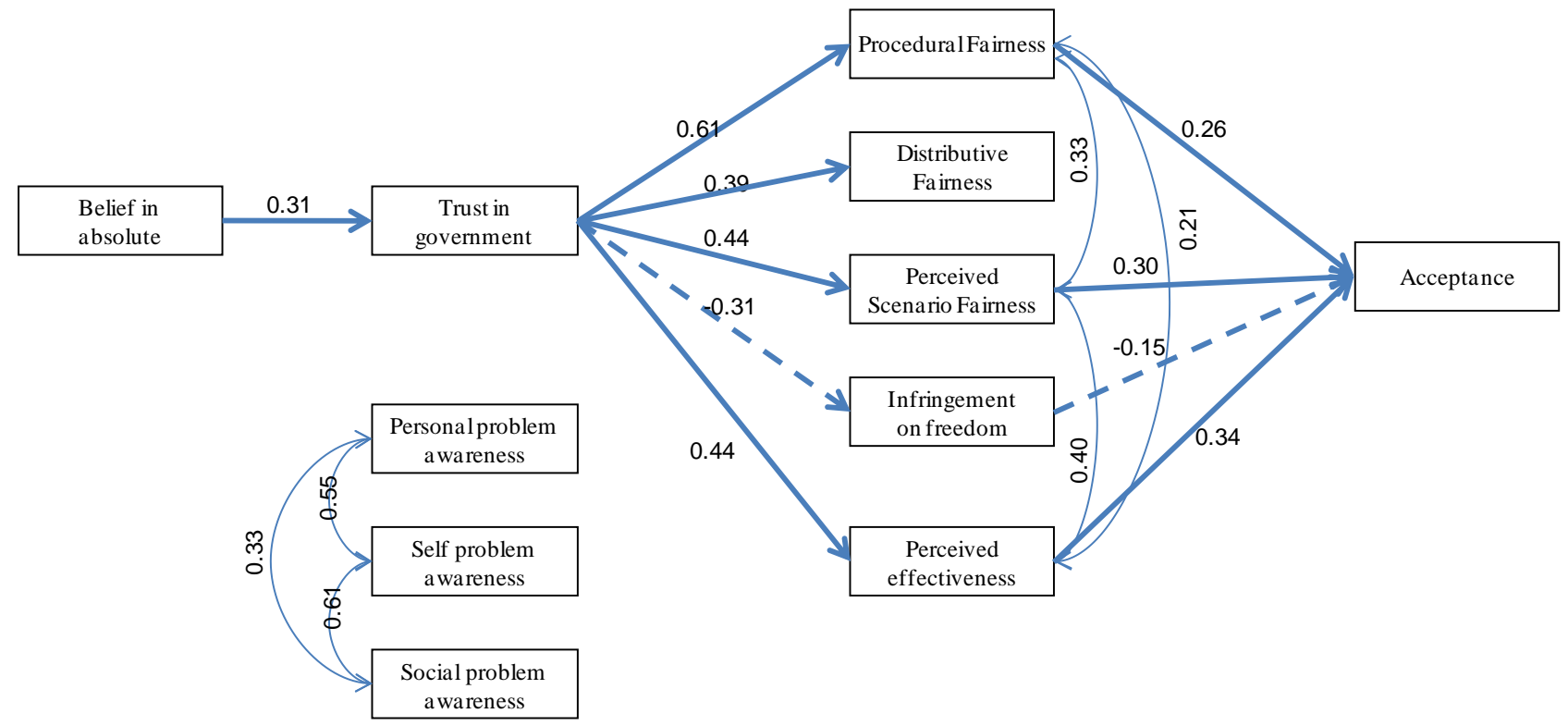

Figure 2 SEM Analysis results of our British sample (thick arrows indicate paths significant at the $5 \%$ level; thin two-way arrows indicate correlations, dotted arrows indicate negative paths/correlations) 


\section{Conclusions}

The correlation analysis suggests that in both countries the following scheme specific variables are significant determinants for the acceptance of coercive policies such as road pricing: Scenario fairness, distributive fairness, procedural fairness, infringement on freedom, social problem awareness and perceived effectiveness. We can thus conclude that the psychological factors itself do not importantly differ between Japanese and British in our sample. Our path analysis suggests, however, that the role of perceived effectiveness is more pronounced in the British sample possibly suggesting that there are some cultural differences and that the effects reported in the literature differ to some degree when non-European samples are taken.

Our findings have some policy implications. Firstly, for coercive policies such as road pricing it is difficult to gain acceptance without considering various aspects of fairness in both Japan and the U.K. Therefore, it is important for decision makers to explain the implications of do-nothing policies as well as how decisions were derived. This is especially important in the U.K. where we find a direct link between procedural fairness and acceptance. For example the process that leads to a decision to introduce road pricing should be transparent and once a decision for a road pricing policy has been made the public should be informed not only about the scheme and its advantages but also about the consequences for the city and different population groups if such a decision would not have been made. The perceived infringement in our study is purely a financial one. Obviously the amount charged will influence acceptance, how sensitive acceptance is to the amount of tax or road charge is, however, beyond the scope of this study. Further, for transport policy schemes, it might be interesting to disentangle the effect of different forms of infringement (financial, movement) that are often imposed by the same scheme.

The focus of our analysis is on the perception of government. Through correlation analysis our analysis firstly confirms the importance of government trust in gaining acceptance in both cultures. Path analysis then shows its effect on acceptance is mediated through scheme specific determinants in both samples. This result is compatible with previous findings by Fujii (2005) also using Japanese data. It confirms that these findings can be replicated in Britain, a western country. Furthermore, these mediation effects are more complete in the British sample whereas in the Japanese sample government trust itself remains a significant determinant of acceptance. Therefore, in addition to specific explanations about the proposed scheme, policy makers in Japan should strongly care about people's general trust in their overall policy. Provocatively speaking, one might even argue that the scheme specifics in Japan are less important but that acceptance will be gained if people trust the government and understand that there is a problem. 
This paper proposes that "belief in absolute" is a suitable underlying or "deeper" value to partially describe whether individuals are likely to accept a coercive policy, where trust in government fulfils a mediational role. Our data analysis with a British sample confirms our presumption. Namely, belief in absolute is a significant value only for the British sample. Our theoretical justification might be that in Western cultures the concept of government is somehow related to the concept of absolute. This means that those accepting absolute values are more likely to trust their government, their policy suggestions and the way a government derives decisions.

Our results are further in line with our presumption that absolute beliefs will have less significance in countries with strong polytheistic or pantheistic backgrounds. Our reasoning is that polytheistic beliefs, such as Buddhism or Hinduism, encourage thoughts that value sets will depend on which God is given higher priority. In cultures with such religious background there is much less of a claim that one's own value set should be the same for all humans. Further, pantheistic beliefs do not define absolute values. It should be emphasised that we do not presume that today's British people in general have a higher belief in absolute values than Japanese, but we show that the effect of belief in absolute values on the perceptions regarding government is different. In Britain and many other countries the influence of the church has long been declining and ideas of absolute values appear to become unpopular and often linked to fundamentalism. In conclusion, our paper proposes that "absolute values" might be one suitable determinant for understanding the role of government for the acceptance of coercive policies in Western cultures. Since we obtained a fairly low reliability factor for our proposed determinant further research should confirm this, possibly by refining the questions used in a survey. Eagerly and Chaiken (1993) summarise some approaches to verify conclusions on the importance of attitudes, such as known group comparisons, multiraid-multimethod matrices or repeating the surveys with different wordings that might be employed in future research.

We believe that this exploratory research on the effect of belief in absolute, which might at first appear far from road pricing, also has important implications. That is, especially in the U.K., it might be more difficult to get acceptance for coercive policies in a postmodern society in which every belief becomes relative rather than absolute. Cipriani (2009) discusses the changes in religious beliefs across Europe towards a more pluralistic society in which cultural and religious boundaries are fading. Though understanding and acceptance of other cultures and beliefs are certainly desirable, some wider impacts of this change might still be underestimated. Compared to this, our analysis suggests that this effect of a change in people's beliefs from "absolute" to "relative" values might not be as strong in Japan. 
In further work one should not only expand the sample size beyond our limited sample of students. Further, clearly other deeper determinants than belief in absolute might also have significant effects on acceptance and its determining factors. Belief in absolute seems to be more compatible with a Christian background. To better understand the acceptability of coercive policies in Japan, other deeper determinants that might be more compatible with a population based on Buddhism and Confucianism should be investigated. Hatori and Fujii (2008), for example, propose that a measure of "arrogance", related to a person's self confidence and disrespect of other's opinions and interests, can explain a person's willingness to co-operate in social dilemma situations. Further work could investigate whether such a measure might also explain a willingness to accept coercive policies such as road pricing.

\section{References}

Bamberg S, Rölle D. 2003. Determinants of people's acceptability of pricing measures: replication and extension of a causal model. In: Schade J, Schlag B (eds.), Acceptability of Transport Pricing Strategies. Elsevier, Oxford, pp. 235-248.

Baron J, Jurney J 1993. Norms against voting for coerced reform, Journal of Personality and Social Psychology, 64, 347-355.

Cipriani R. 2009. Religions in Europe. Religion, 39 (2), 109-116.

Choocharukul K, Fujii S. 2007. Psychological Factors Influencing Behavioral Intention of Private Car Use in Future Work Trips. Journal of the Eastern Asia Society for Transportation Studies, 7, 211-222.

Eagerly A, Chaiken S. 1993. The Psychology of Attitudes. Harcourt Brace College Publishers

Ecola E, Light T. 2010. Making Congestion Pricing Equitable. Paper presented at the $89^{\text {th }}$ Annual Meeting of the Transportation Research Board, Washington D.C., January 2010.

Fujii S, Gärling T, Jakobsson C, Jou RC. 2004. A cross-country study of fairness and infringement on freedom as determinants of car owners' acceptance of road pricing, Transportation, 31, (3), pp. 285-295.

Fujii S. 2005. A condition of development of trust toward public administration, Japanese Journal of Experimental Social Psychology, 45 (1): 27-41 (In Japanese with English abstract)

Gärling T, Fujii S, Gärling A, Jakobsson C. 2003. Moderating effects of social value orientation on determinants of proenvironmental behaviour intention, Journal of Environmental Psychology, 23 (1): 1-9.

Gärling T, Jakobsson C, Loukopoulos P, Fujii S. 2008. Acceptability of road pricing. In Verhoef E, Bliemer E, Steg L, Van Wee B (eds.), Pricing in road transport: Multidisciplinary perspectives, Cheltenham, UK: Edward Elgar.

Gaunt M, Rye T, Allen T. 2007. Public Acceptability of Road Pricing: The Case of Edinburgh and the 2005 Referendum. Transport Reviews, 27(1): 85-102. 
Hansla A, Gamble A, Juliusson A, Gärling T. 2008. The relationships between awareness and consequences, environmental concern, and value orientations. Journal of Environmental Psychology, 28(1): 1-9.

Hardin R. 1999. Do you want to trust in government? In: Warren, M.E. (ed.), Democracy and Trust, Cambridge University Press, pp. 22-41.

Hatori T, Fujii S. 2008. The mass man as defector: Implications of Ortega's "the rebellion of the masses" on social dilemma research, The 29th International Congress of Psychology, International Journal of Psychology, Vol. 4(3): 431.

Jakobsson C, Fujii S, Gärling T. 2000. Determinants of private car users' acceptance of road pricing. Transport Policy 7 (2): 153-158.

Jones P. 2003. Acceptability of Road User Charging: Meeting the Challenge. In: Schade J, Schlag B (eds.), Acceptability of Transport Pricing Strategies. Elsevier, Oxford, pp. 27-62.

Lind EA, Tyler TR. 1988. The Social Psychology of Procedural Justice. Plenum Press, New York.

Loukopoulos P, Jakobsson C, Gärling T, Schneider CM Fujii S. 2005. Public Attitudes towards Policy Measures for Reducing Private Car Use, Environmental Science \& Policy, 8: 57-66.

Offe C. 1999. How can we trust our fellow citizens? In Warren ME (ed.), Democracy and Trust, Cambridge University Press, pp. $42-87$.

Piriyawat S, Tan VH, Fujii S. 2009. The Roles of Perceived Effectiveness and Problem Awareness in The Acceptability of Road Pricing in Bangkok. Songklanakarin Journal of Science and Technology, 31(2): 181-188.

Quddus MA, Bell MGH, Schmöcker JD, Fonzone A. 2007. Impact of the Congestion Charge on Retail Business in London: An Econometric Analysis. Transport Policy, 14(5): 433-444.

Räthel N, Uzzel D. 2009. Changing relations in global environmental change. Global Environmental Change, 19: 326-335.

Rokeach M. 1973. The nature of human values. The Free Press, New York.

Schade J, Schlag B. 2000. Acceptability of urban transport pricing. VATT Research Reports, 72. Helsinki: VATT.

Schade J, Schlag B. 2003. Acceptability of Transport Pricing Strategies. Elsevier, Oxford.

Schaller B. 2010. New York's Congestion Pricing Experience and Implications for Road Pricing Acceptance in the United States. Paper presented at the $89^{\text {th }}$ Annual Meeting of the Transportation Research Board, Washington D.C., January 2010.

Schmöcker JD, Fonzone A, Quddus MA, Bell MGH. 2006. Changes in the frequency of shopping trips in response to congestion charge. Transport Policy 13 (3): 217-228.

Schultz PW, Zelezny L. 1999. Values as predictors of environmental attitudes: Evidence for consistency across 14 countries. Journal of Environmental Psychology, 19 (3), 255-264. 
Schwartz SH. 1992. Universals in the content and structure of values: Theoretical advances and empirical tests in 20 countries. In M. Zanna (Ed.), Advances in experimental social psychology, 25, 1-65. New York: Academic Press.

Schwartz SH. 1994. Are there universal aspects in the structure and contents of human values? Journal of Social Issues, 50(4): 19-46.

Steg L. 2003. Factors Influencing the Acceptability and Effectiveness of Transport Pricing. In: Schade J, Schlag B (eds.), Acceptability of Transport Pricing Strategies. Elsevier, Oxford, pp. 187-202.

Taylor BD, Iseki H, Kalauskas R. 2010. Addressing Equity Issues in political debates over road pricing. Paper presented at the $89^{\text {th }}$ Annual Meeting of the Transportation Research Board, Washington D.C., January 2010.

Triandis H. 1995. Individualism and Collectivism, Westview Press. 